\title{
AI Technology Application in Medical Care of NSCLC Based on Patent Trend Analysis
}

\author{
Cheng-Wen Lee ${ }^{1}$ and Shu Hui Chen ${ }^{2}$
}

\begin{abstract}
The patent trend analysis provides sound knowledge about the possibility of exploring potential innovation/R\&D and gives an insight into which countries and companies are mostly investing in artificial intelligence (AI) technologies involved with non-small cell lung cancer (NSCLC) medical care. By comparing patent indicators changes of two decades from 2001 to 2020, the most active countries and companies are identified to provide perceptions of global patent variations. In line with this, we apply a comprehensive software INNOVUE to analyze the patent trend based on the Worldwide Patent Office database. According to previous research, 315 patents are selected as the appropriate patent analysis data. The analysis result is a series of trend maps that show the trend of patent development from the early stage to current changes. This study findings evaluate government's/company's concern and motivation about the investment in R\&D capability of AI technologyrelated patents, and indicate who plays the main role around the world regarding the application of AI combined with NSCLC medical treatment.
\end{abstract}

JEL classification numbers: C80, D81, E27.

Keywords: Patent trend analysis, Artificial intelligence technologies, NSCLC.

${ }^{1}$ Department of International Business, Chung Yuan Christian University, Taoyuan City, Taiwan.

2 Ph.D. Program in Business, College of Business, Chung Yuan Christian University, Taoyuan

City, Taiwan.

Article Info: Received: September 28, 2021. Revised: October 15, 2021.

Published online: October 19, 2021. 


\section{Introduction}

With the increasingly fierce global technological competition, organizations from all over the world have carried out patent strategy research. The core of analysis patent trend is to processing, and transform this information into competitive intelligence with overall and predictive functions. This paper aim to focuses on the lately most popular discussion topic of artificial intelligence (AI) technology application in the highest fatality disease NSCLC.

About Lung cancer there are many vital facts we should pay attention. Over two million cases of lung cancer are diagnosed annually, according to the World Health Organization (WHO), non-small cell lung cancer (NSCLC) accounts for the majority of all lung cancer cases. According to Zappa and Mousa (2016), lung cancer has a poor prognosis as over half of people diagnosed with lung cancer die within one year of diagnosis. The 5-year survival rate is less than $18 \%$.

Oncologists consider lung cancer is most challenged by a huge and rapidly expanding knowledge base. Oncologists who are experts in a specialized field cannot master all available knowledge. Doctors at the primary level are requested to task with tackling numerous tumor types. Also, the distribution of medical resources is not balanced. Medical specialist knows the growth of massive genetic and clinical databases need to be accelerated toward high speed of lung cancer treatment advances and be cut down the cycle time for modified lung cancer treatment guidelines.

Matching patients to the most effective therapy currently requires specimen-based assays. In addition to tissue-based biopsies being an invasive procedure, malignant tumors can be heterogeneous and the biopsied tissue can be used for testing nonreflective of the entire tumor. Thus, artificial technology could assist medication care by effective progression and identified massive information. During the diagnosis process, tumors can mutate during a course of therapy, and further render the initial treatment ineffective.

Recently, AI has been demonstrating remarkable success in medical care and analysis owing to the rapid progress of "deep learning" algorithms, which have shown increasing power to solve complex, real-world problems in computer vison and image analysis (Wang et al., 2019). Lung cancer is a serious health problem and also is the leading cause of cancer death worldwide due to its high incidence and mortality. According to World Health Organization (WHO) statistics, about $80 \%$ to $85 \%$ of lung cancers are none small cell lung cancer (NSCLC), the common existing with a locally advanced or metastatic disease (Kashf et al., 2018).

\section{Literature Review}

\subsection{The current NSCLC medical treatment}

Most NSCLC can be grouped into three main categories: Squamous Cell Carcinoma, Adenocarcinoma and Large Cell Carcinoma Histo-subtypes. NSCLC is sorted by when the type of lung cell the cancer begins and by how the cells appear under a 
microscope. There are slight differences among the three main categories. However, they incline to the same view (prognosis) and common treatment using similar way. The three main treatments in current NSCLC medical care are as follows:

(1) Surgery: For patients who have stage I, II, and III, typically NSCLC treatment would have surgery to remove the tumor if the tumor is found to be respectable and meanwhile, the patient is able to tolerate the surgery. To determine whether or not the tumor is respectable, imaging studies and biopsies are decided by physician's profession to complete an evaluation of the patient's factors of leading the patient's operability.

(2) Chemotherapy: Approximately $40 \%$ of newly diagnosed lung cancer patients are in stage IV. The specific combination of chemotherapy depends on types and frequencies of toxic effects and doctors should be decided on an individual basis. However, overall median survival for patients was approximately $8-10$ months.

(3) Radiotherapy: Using high-energy beams to damage DNA within cancer cells, and thereby to destroy neoplastic cells. This therapy can help eliminate or control tumors at specific sites. This therapy may benefit patients with NSCLC that is localized to the chest or who are not candidates for surgical resection.

Besides histological, clinical and demographic information, a wide range of data ranging from genomics, proteomics, immunohistochemistry and imaging must be integrated by physicians while developing personalized treatment plans for patients which can be challenging and lead to unfavorable outcomes. Furthermore, there are a number of factors that timely limit access to these tests, including high cost and late availability in the patient care continuum (Rabbani et al., 2018). Accordingly, the reasons mentioned above could make "time" saving became a critical issue for NSCLC patients. Early diagnosis, even gene analysis, and image learning could provide great support for medication care and might lead better survival rate. Comparing with shallow learning methods, AI technology has multiple advantages in analyzing pathology images and power in recognizing complex objects, including simplification of feature definition, time-saving through parallel computation, and suitability for transfer learning. Eventually, an urgent need may be considered for AI technology applied in NSCLC medical care.

\subsection{AI technology application}

Artificial intelligence (AI) aims to mimic human cognitive functions. It is bringing a paradigm shift to healthcare, powered by growing availability of healthcare data and rapid progress of diagnosis and analytics techniques (Jiang et al., 2017). AI has been well-known as the area of computer science dedicated to producing programs capable of refined and intelligent computations like those that the human brain regularly makes. AI contains approaches, tools and systems dedicated to simulate human procedures of logical and inductive knowledge acquisition, reasoning of brain doings for resolving problems (Kashf et al., 2018). It is believed it is the future of the medical treatment, also the survival hope for NSCLC patients. 


\subsection{Urgent needs and further AI technology development}

In current clinical practice, cancer diagnosis begins when a patient presents with a suspicious lesion on screening or signs and symptoms considered consistent with a diagnosis of lung cancer. Imaging modalities used to evaluate the presence and extent of cancer, including computed tomography (CT), single-photon emission computed tomography (SPECT), magnetic resonance imaging (MRI) and $18 \mathrm{~F}$ fluorodeoxyglucose positron emission tomography-computed tomography (18FFDG PET-CT) (Rabbani et al., 2018).

Liu (2020) claims that AI has been shown to be able to help clinicians make more accurate judgments and decisions in many ways. In an attempt to increase the information obtained from medical images and assist radiologists, new approaches that use machine learning methods to detect and diagnose lung nodules could detect and diagnose tumors as small as $3 \mathrm{~mm}$. The strengths of AI are well suited to overcome the challenge posed by the current generation of targeted and immunotherapies, which can produce a clear clinical benefit (Bi et al., 2019).

New technology is new urgently needed for not only medication care and treatment, but also detection at the early stages of NSCLC. It has been involved in the screening of lung cancer, the classification of histological cancer, judge of benign and malignant degree of pulmonary nodules, to differentiate of histological subtypes, identified of genomics, the judgment of the effectiveness of treatment. To be more precise, what distinguishes AI technology from traditional technologies in health care is the ability to gather data, process it and give a well-defined output to the end-user.

\section{Research Methodology}

With the assistance of the software INNOVUE, a patent search strategy was quickly drawn up. In the AI technology part, this study conducts the analysis through the data of seven main patent authorities as USPTO, WIPO, EUIPO, CNIPA, JPO, KIPO, and TIPO to search AI patent statistics. This examination allows us to identify possible international based on patent indicators that permit rigorous crosscountry comparisons of innovation performances at national and sectional levels based on Rabbani et al. (2018). Their research is to clarify the role of artificial intelligence in the care of patients with non-small cell lung cancer. According to Rabbani et al. (2018), we conclude 10 keywords used to investigate in the fields of subject matter, abstract, and scope of patent application. The scope of medical considerations is considerably diverse. From measurement, monitoring, medical care, diagnosis, machine learning, deep learning, treatment, and medical materials, we match with 10 International Patents Classification (IPC) to intersect related applications in the medical field for supplementary search and analyze AI technology-related patents from 1986 to 2021 (see Table 1). 
To ensure data consistency and relevance across the collection, only patents composed of the following ten keywords in their titles, or contents are retrieved. The ten key words are NSCLC, artificial intelligence, machine learning, neural network, logic programming, expert system, lung cancer, big data, oncology engineering, and deep learning.

Table 1: International patents classification from 1986 to 2021

\begin{tabular}{|c|c|}
\hline IPC code & Description \\
\hline G01N & $\begin{array}{l}\text { Investigating or analyzing materials by determining their chemical or } \\
\text { physical properties }\end{array}$ \\
\hline C12Q & $\begin{array}{l}\text { Measuring or testing processes involved enzymes or microorganisms, } \\
\text { compositions or test papers therefore, processes of preparing such } \\
\text { compositions }\end{array}$ \\
\hline A61K & $\begin{array}{l}\text { Preparations for medical, dental or toilet purposes absorbent pads or } \\
\text { surgical articles, soap compositions }\end{array}$ \\
\hline $\mathrm{G} 16 \mathrm{H}$ & $\begin{array}{l}\text { Information and communication technology specially adapted for } \\
\text { specific application fields. }\end{array}$ \\
\hline $\mathrm{C} 07 \mathrm{~K}$ & Peptides, genetic engineering processes for obtaining peptides \\
\hline G06N & Computer systems based on specific computational models \\
\hline G06F & Electric digital data processing \\
\hline G06T & Image data processing or generation in general \\
\hline $\mathrm{C} 12 \mathrm{~N}$ & $\begin{array}{l}\text { Microorganisms or enzymes, compositions propagating, preserving, or } \\
\text { maintaining microorganisms, mutation or genetic engineering, culture }\end{array}$ \\
\hline $\mathrm{A} 01 \mathrm{~N}$ & Preservation of human bodies or animals or plants or parts of biocides \\
\hline
\end{tabular}

Source: https://www.uspto.gov/web/patents/classification/20210630 
By applying the INNOVUE software system, 462 patents related with AI technology application for NSCLC are found from 1986 to 2020. Manually checked and deducted, the patents whose concepts of AI are not consistent with the proposed definition related with NSCLC are then excluded, despite having keywords appearing in contents or subject heading. In the result, 315 patents are filtered for relevance by analyzing or skimming the content. This research methodology process is illustrated in Figure 1.

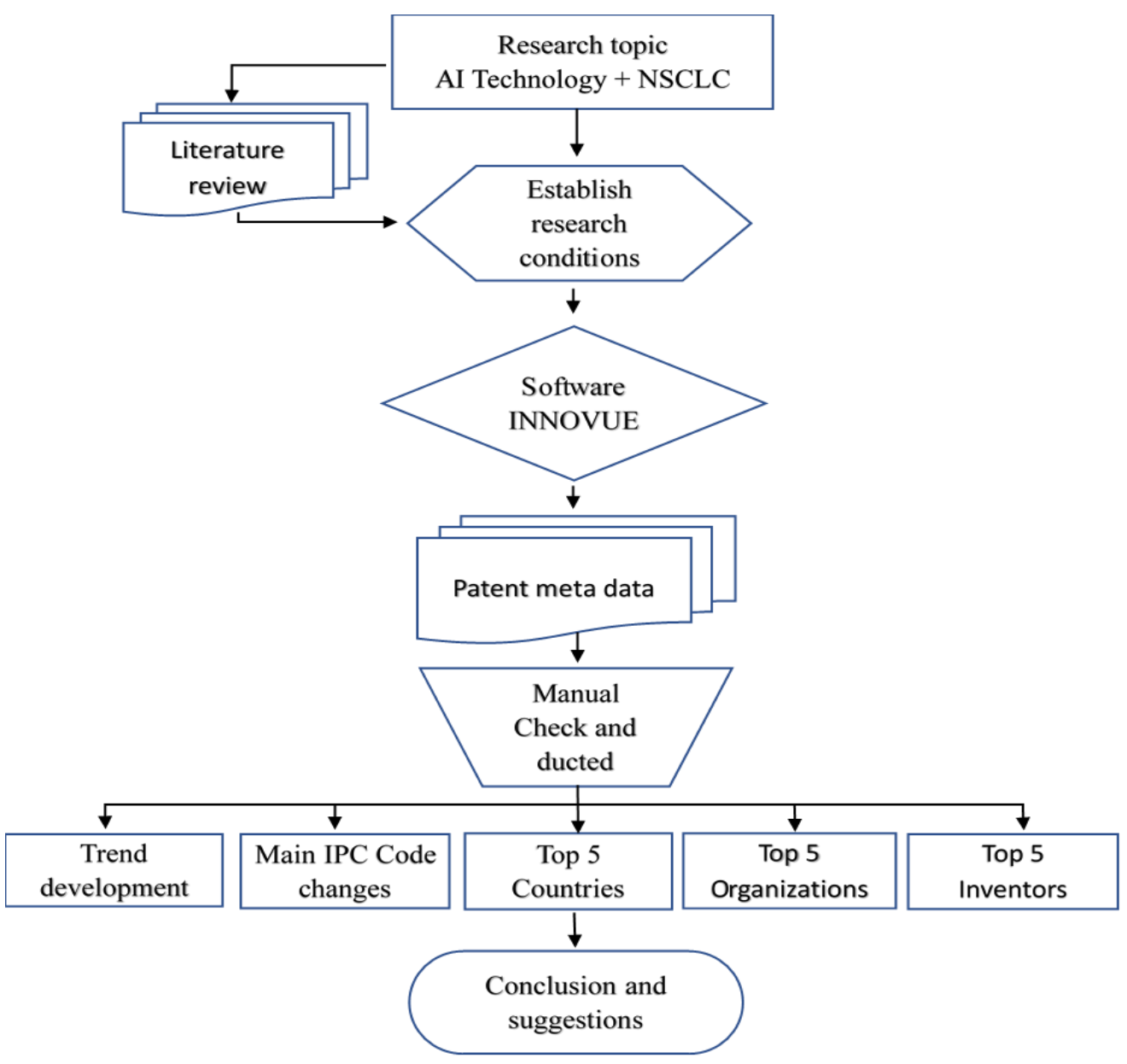

Figure 1: Research methodology process 


\section{Data and Result Discussion}

\subsection{The increasing trend of patent development}

As shown in Figure 2, the AI technology-related patents applied in NSCLS are firstly announced in 1986. Since then, the number of AI technology-related patents has slowly increased in the following 15 years. After 2001, it seems to revel some concentration in this research field. 36 patents announced in 2019, the patents number comes dramatically growth two times more than previous year (16 patents announced in 2018). In 2020, the growth remains rapid increases to 54 patents announced. From this trend development, AI technology application in the medical care of NSCLC is obviously progressing in an optimistic pattern.

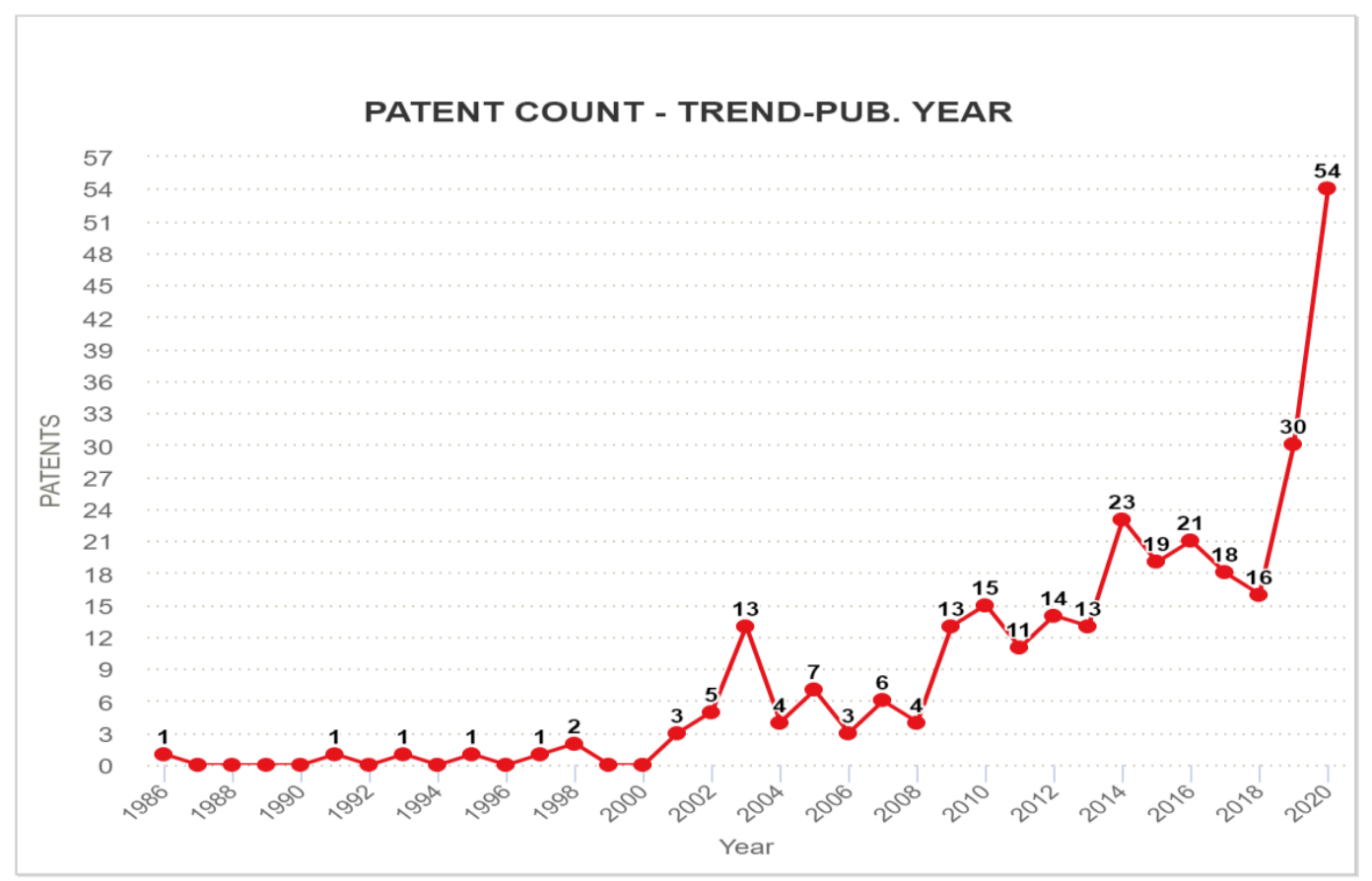

Figure 2: AI technology patents applied in NSCLS (1986-2020)

Consequently, Figure 3 shows that the trend of AI technology application in NSCLC development have changed in every 10 years. From 1986 to 2001, there is a passive growth in the early stage. Not much patent is announced during the first period. After 2001, it seems that the progressing pattern has significant increased. More researchers has involved in this field, and thus the notion of AI technology applied in NSCLC treatment finally gather intention of it deserved. Therefore, this study compares the observation of two decades to analyze the patent development. First decade is defined as 2001 year to 2010 year. During this ten years, 73 patents are published. The steady increasing patent number represents a growth of AI technology submitted to an application in NSCLC medical treatment. The next decade of 2011 year to 2020 year, 219 patents are published and the number of 
patents published has spectacularly increased. The increasing pattern shows that there is noticeable need for AI technology applied in NSCLC treatment.
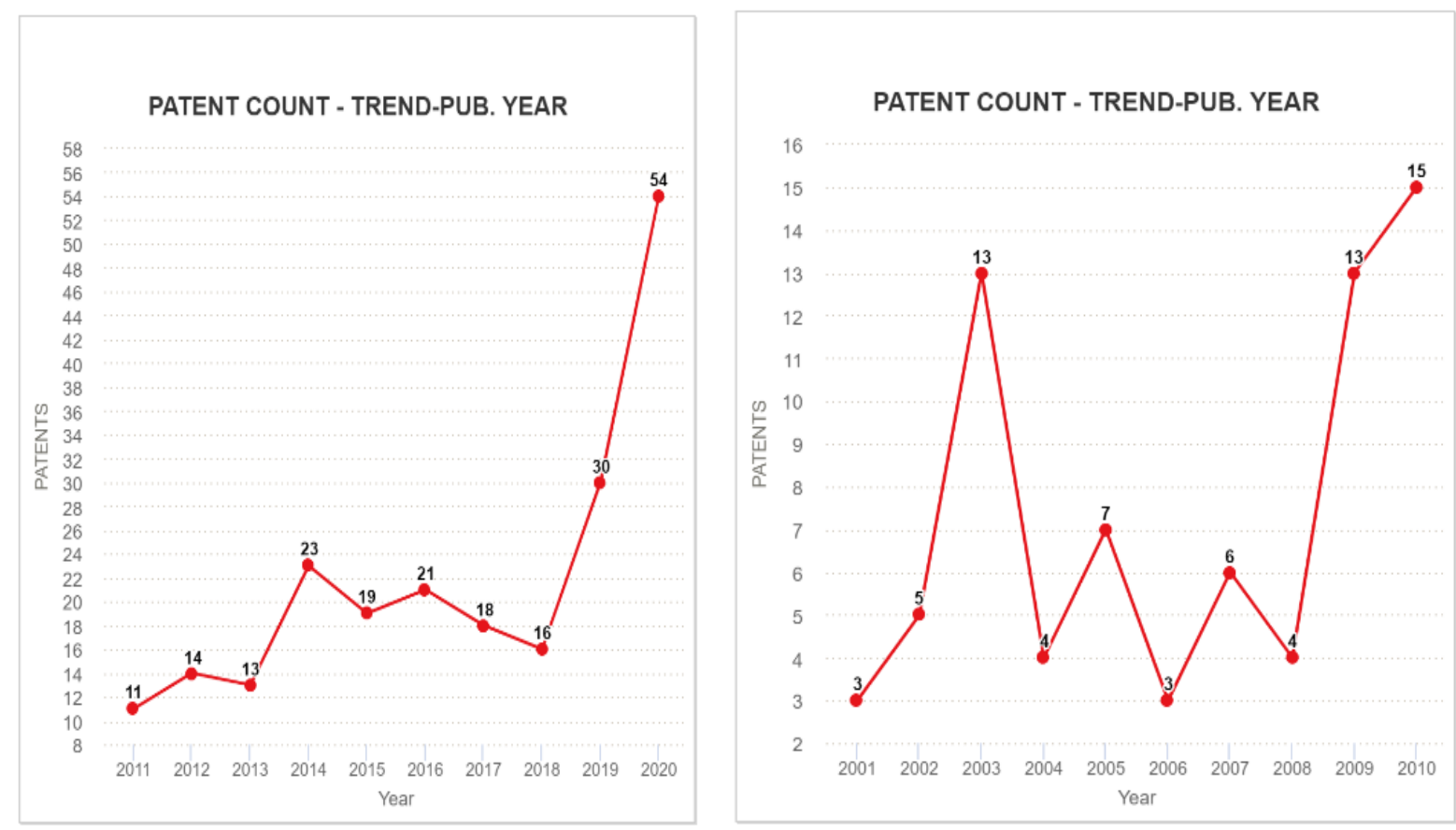

Figure 3: Comparing two decades during 2001-2010 vs. 2011-2020

\subsection{Main IPC analysis}

The IPC system is used by more than 100 different patent offices around the world. Each classification code has its own particular description and reveals the technical contents of a patent. From Figure 4 and Figure 5, we can observe the trend in the previous ten years, herewith C12Q $1 / 00$ attracting the most interest. In the next decade, C12Q 1/00 falls to the second place (top 5 patents). G01N 33/00 previously is just in the second priority position and contrarily, becomes most popular in the following decade. A61K 39/00 has swapped by A61 31/00. G06K 9/00 and G06T $7 / 00$ patents distributions have replaced those of $\mathrm{C} 07 \mathrm{H}$ 21/00 and $\mathrm{A} 61 \mathrm{~K} 31 / 00$. 


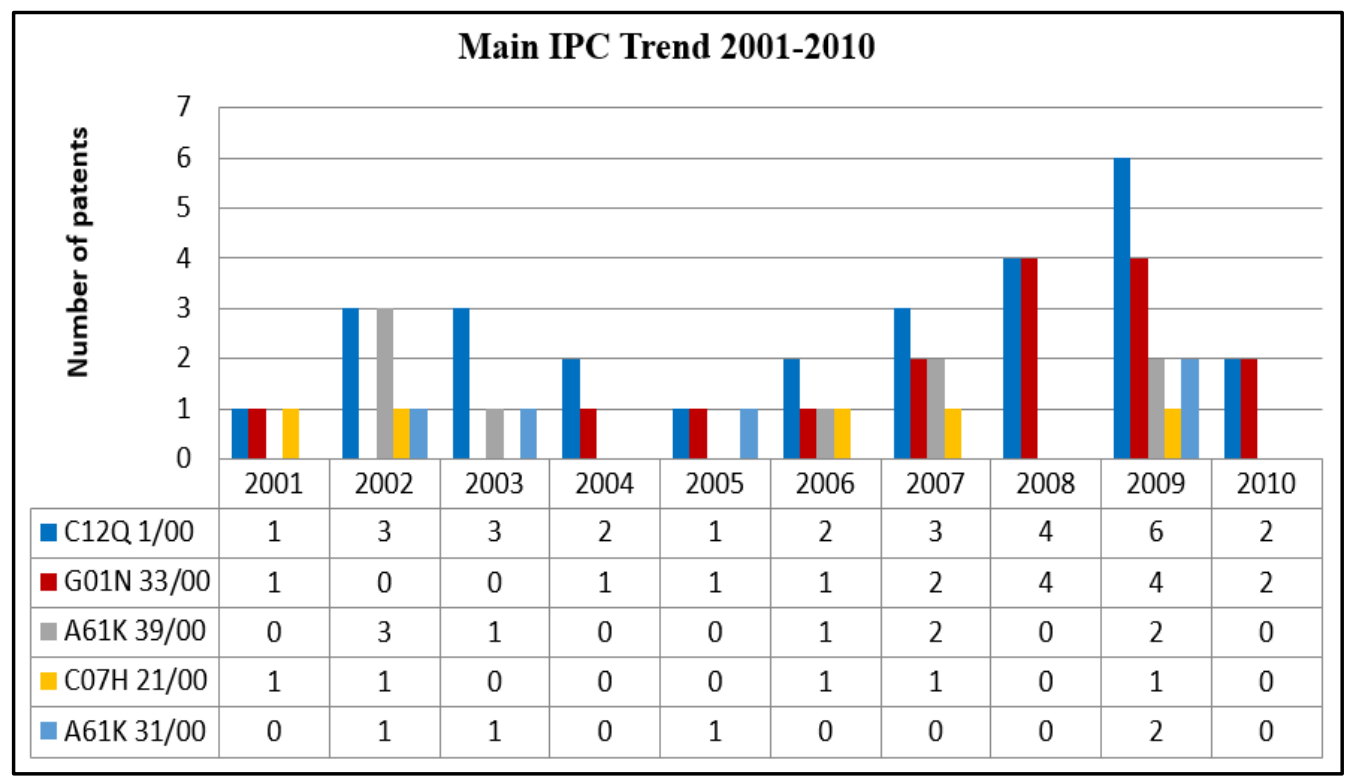

Figure 4: Main IPC trend of 2001-2010

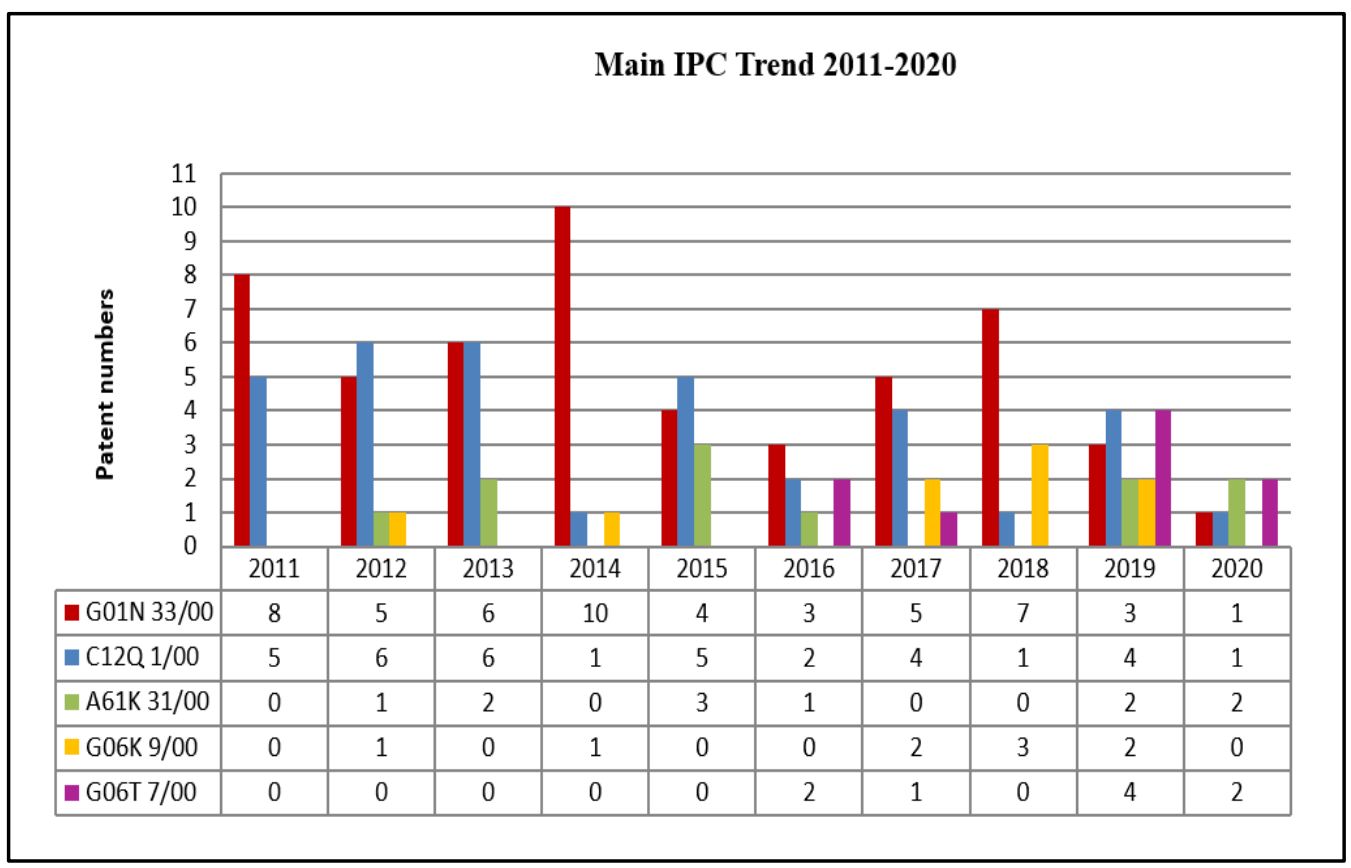

Figure 5: Main IPC trend of 2011-2020 
Table 2: The main IPC code of AI technology applied in NSCLS (2001-2020)

\begin{tabular}{|l|l|}
\hline Main IPC & \multicolumn{1}{c|}{ Descriptions } \\
\hline G01N 33/00 & $\begin{array}{l}\text { Investigating or analyzing materials by specific methods not } \\
\text { covered by groups G01N 1/00-G01N 31/00 }\end{array}$ \\
\hline C12Q 1/00 & $\begin{array}{l}\text { Measuring or testing processes involved enzymes, nucleic acids or } \\
\text { microorganisms, compositions therefore, processes of preparing } \\
\text { such compositions }\end{array}$ \\
\hline A61K 31/00 & Medicinal preparations containing organic active ingredients \\
\hline A61K 39/00 & Medicinal preparations containing antigens or antibodies \\
\hline G06K 9/00 & $\begin{array}{l}\text { Methods or arrangements for reading or recognizing printed or } \\
\text { written characters or for recognizing patterns, e.g. fingerprints }\end{array}$ \\
\hline G06T 7/00 & Image analysis \\
\hline A61K 31/00 & Medicinal preparations containing organic active ingredients \\
\hline C07H 21/00 & $\begin{array}{l}\text { Compounds containing two or more mononucleotide units to } \\
\text { separate phosphate or polyphosphate groups linked by saccharine } \\
\text { radicals of nucleoside groups, e.g. nucleic acids }\end{array}$ \\
\hline
\end{tabular}

Source: https://www.uspto.gov/web/patents/classification/20210630

Generally, the measuring or testing processes involved enzymes, nucleic acids or microorganisms and investigating or analyzing materials by specific methods are crucial at the previous stage of patent innovation. Medicinal preparations containing antigens or antibodies are changed to organic active ingredients. The methods for arrangement reading or recognizing patterns and image analysis are become increasing important lately. Deep learning model that quantitatively track changes in lesions over time may help clinicians tailor treatment plans for individual patients and also stratify patients into different risk groups for clinical trials.

Wang et al. (2019) claim that artificial intelligence, especially deep learning, has shown great potential in tumor region identification, prognosis prediction, tumor microenvironment characterization, and metastasis detection by applying pathology image analysis tasks.

\subsection{Main players/countries}

For reasons well-known to all, the patent innovation could be very financial and human power consuming. Most of time, the AI technology-related patent issued could be a mission impossible without governmental/corporation's financial support or subsidization. As Raghupathi, V. and Raghupathi, W. (2019) declare, countries governments play a key role by attaining a level of endogenous innovation using multifaceted incentives for science and technology indicators. 

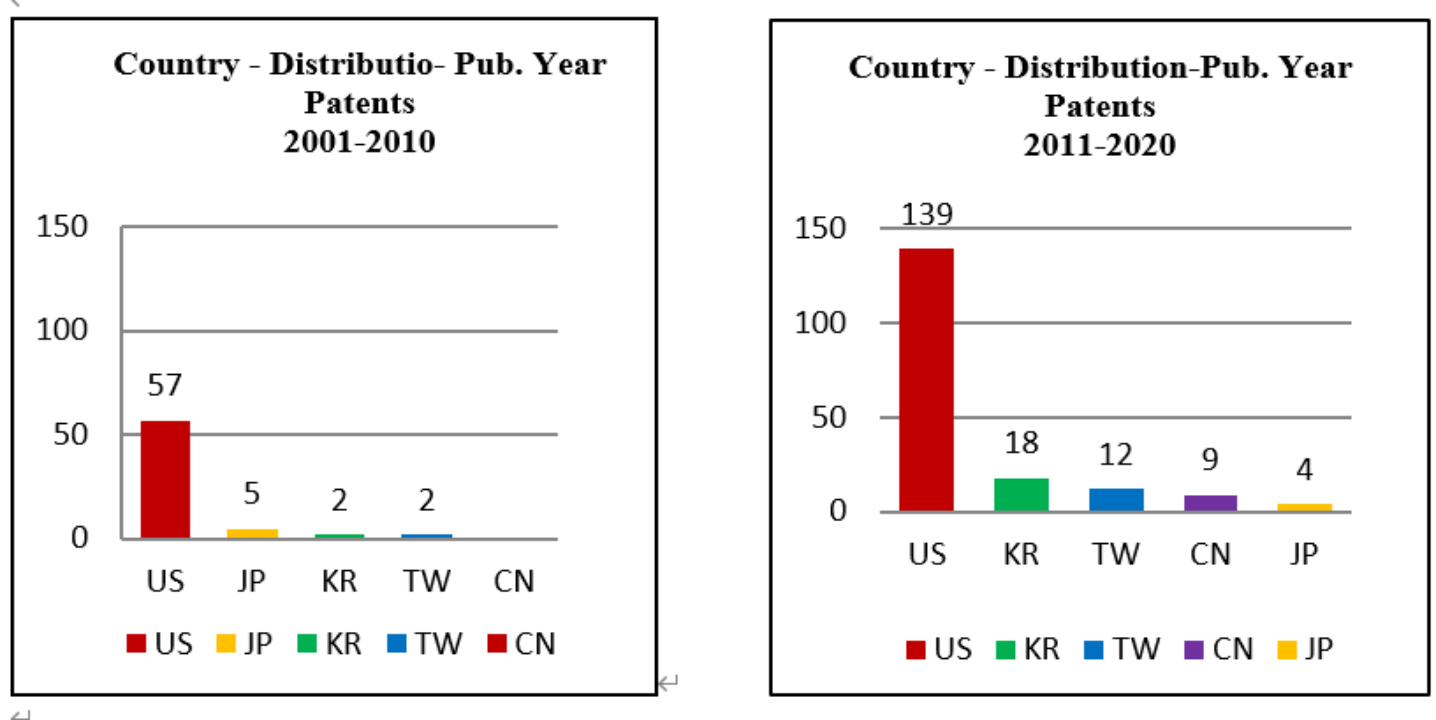

\section{Figure 6: AI technology patents applied in NSCLS during} 2001-2010 vs. 2011-2020

From 2001 to 2010, the top five countries of AI technology-related patents are US, Japan, Korea, Taiwan and China in ranking order (see Figure 6). According to Abadi et al. (2020), from the beginning to the end of 2018, more than 123,500 AIrelated patents are granted by the USPTO. The United States has the highest number of AI-related patents $(87,244)$, followed by Japan $(9,787)$ and Korea $(4,798)$. Not surprisingly, the USPTO have been the most patent application country in the world even in the modern technology development of the AI. Despite from the US, the other top four countries are all from Asia. After 2010, although the countries ranking has slightly changed, except from the US, the AI technology-related patents with NSCLC still devote interested within Asia countries. From 2010 to 2020, Korea has become the second large source of the patent distribution country. Japan has fallen down to the fifth place, while Taiwan and China are ranked as the third and fourth main countries. From the current trend development, this study concludes that the force of AI technology applied in NSCLC medical care in Asia cannot be underestimated. Nowadays, the major development resource still remains in the US. 


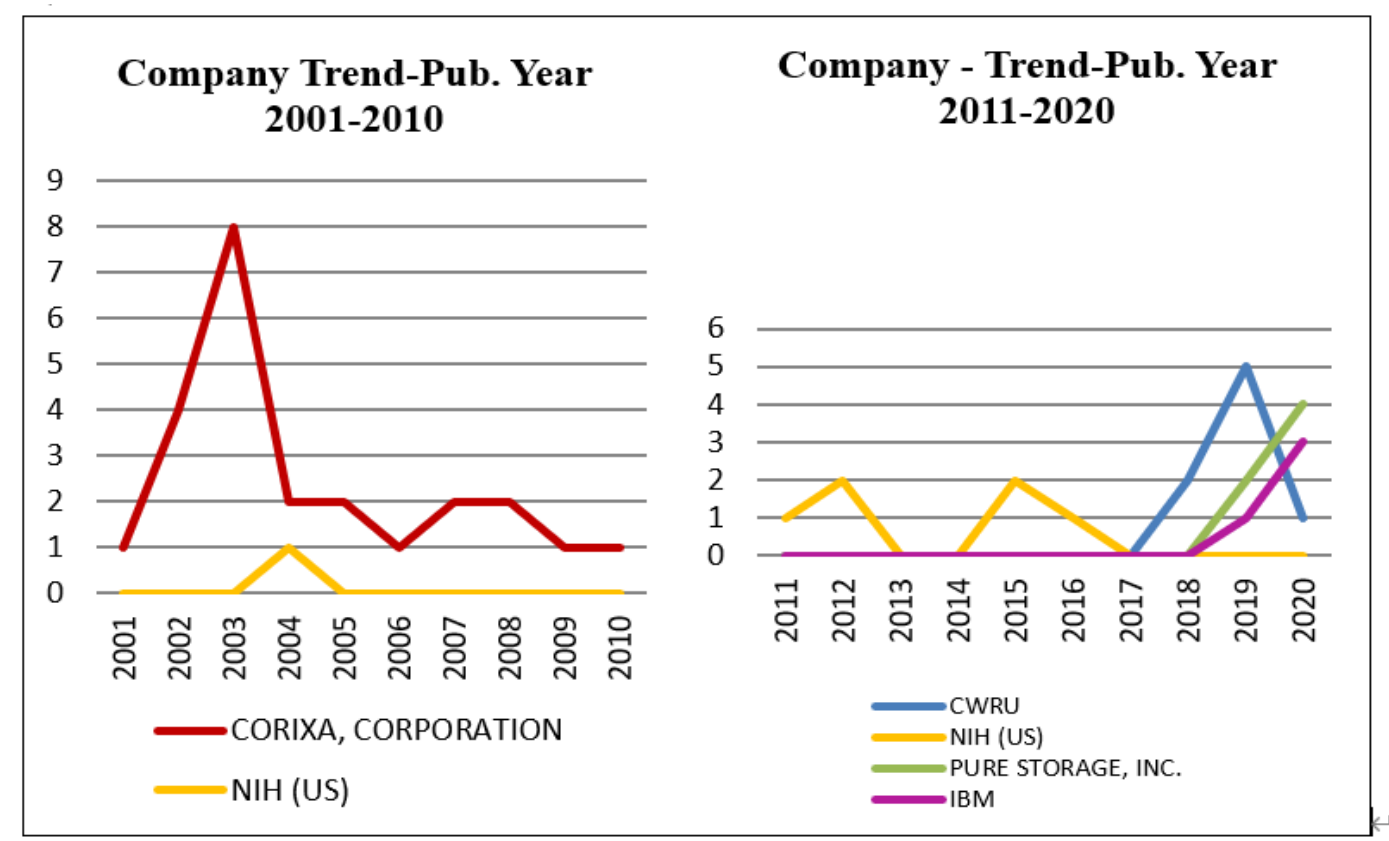

Figure 7: Patents published by companies during 2001- 2010 vs. 2011-2020

The one of commencement, CORIXA Corporation is dominating the AI technology development application of NSCLC medication treatment in 2001-2010, being called as the pioneer of the AI-related research. National Institutes of Health (NIH) also has started to launch the related patent although their research progress is remained less impressive. As can be seen the CORIXA Corporation does not have much influence in 2011 to 2020 . Followed by online news, CORIXA is merged by GlaxoSmithKline (GSK) at March of 2006. This situation explains the reason why the supremacy leader is no longer exists. Instead, Case Western Reserve University (CWRU), IBM, and Pure Storage publish much more patents and show aggressive progress, while the NIH remains moderate interest in the research field.

According to Chen and Chang (2010), market value of companies are highly related with their R\&D-related capabilities, thus they should increase relative patent position and raise patent citations to further enhance their market value. In this software of INNOVIEW, the setting parameters formula of relative R\&D capabilities are shown in Table 3.

R\&D capabilities formula: $\mathrm{Xi}=(5 \mathrm{pc}+2 \mathrm{oc}+1 \mathrm{sc}+1 \mathrm{ic}+0 \mathrm{cc}+-1 \mathrm{py}+0 \mathrm{ay})$,

$\mathrm{M}=\operatorname{MAX}(\mathrm{Xi})$,

Relative R\&D capabilities $=\mathrm{Xi} / \mathrm{M}$. 
Table 3: Parameters of R\&D-related capabilities

\begin{tabular}{|c|c|}
\hline Parameter Items & Default Value \\
\hline Patents (pc) & 5 \\
\hline Other Citings (oc) & 2 \\
\hline Self-Citings (sc) & 1 \\
\hline Inventor Count (ic) & 1 \\
\hline Country Count (cc) & 0 \\
\hline Patent Age (py) & -1 \\
\hline Activity Year (ay) & 0 \\
\hline
\end{tabular}

Table 4: R\&D-related capabilities of the top companies 2001-2010 and 2011-2020

\begin{tabular}{|c|c|c|c|c|c|c|c|c|c|}
\hline Year & Company & Patents & $\begin{array}{c}\text { Other } \\
\text { Citings }\end{array}$ & $\begin{array}{c}\text { Self } \\
\text { Citings }\end{array}$ & $\begin{array}{c}\text { Inventor } \\
\text { Count }\end{array}$ & $\begin{array}{c}\text { Country } \\
\text { Count }\end{array}$ & $\begin{array}{c}\text { Patent } \\
\text { Age }\end{array}$ & $\begin{array}{c}\text { Activity } \\
\text { Year }\end{array}$ & $\begin{array}{c}\text { R\&D } \\
\text { Related } \\
\text { Capabilities }\end{array}$ \\
\hline $2001-2010$ & CORIXA & 18 & 0 & 4 & 29 & 1 & 18 & 7 & $100 \%$ \\
\cline { 2 - 10 } & NIH (US) & 4 & 0 & 0 & 19 & 1 & 14 & 3 & $24 \%$ \\
\hline $2011-2020$ & IBM & 7 & 0 & 1 & 19 & 1 & 3 & 3 & $100 \%$ \\
\cline { 2 - 10 } & CWRU & 8 & 0 & 0 & 11 & 1 & 4 & 4 & $90 \%$ \\
\cline { 2 - 10 } & $\begin{array}{c}\text { Pure } \\
\text { Storage }\end{array}$ & 6 & 0 & 6 & 5 & 1 & 3 & 2 & $73 \%$ \\
\cline { 2 - 9 } & NIH (US) & 3 & 0 & 0 & 11 & 1 & 7 & 2 & $37 \%$ \\
\hline
\end{tabular}

As shown in Table 4, the top companies do not cite from others and seldom cite by themselves except Pure Storage Inc. CWRU has highest amount of 8 published patents while they were actively joining the research field for only 4 years. IBM are considered have highest relative $\mathrm{R} \& \mathrm{D}$ capabilities according to their potential research power of 19 inventors and activity year were only three. Pure storage have lately jointed the related research, have done a notable performance. From Table 4, the number of inventors explains the potential of the R\&D research capabilities. It is worth to take close observation for their future development. The NIH has constantly remained active in the research of AI technology that related with NSCLC medical care. However, from the observation of two decades, AI technology of NSCLC medical application research hasn't been recognized as the key object.

As shown in Table 5, the top 5 inventors are all working for CORIXA Corporation. Tongtong Wang, the main inventor, owns very productive patent inventory rate. $30 \%$ patents are innovated by her and her team pool. Robert A. Henderson is ranked as second dynamic patent innovator. His patents innovation companies are matching with Tongtong Wang. So as other innovators, we may be able to assume that it is very likely they are working as one a single research team. Unfortunately, the highly productive five innovators seem to loss the governmental support and 
their innovation/R\&D and productive capability become less after 2010. As the CORIXA Corporation is merged by GSK, the top five innovators are also no longer exist in the research field.

Table 5: Top 5 inventors of 2001 to 2010

\begin{tabular}{|c|c|c|c|c|c|c|c|}
\hline \multicolumn{4}{|c|}{ From Year 2001-2010 } & \multicolumn{4}{|c|}{ From Year 2011-2020 } \\
\hline Inventor & Company & Patents & $\begin{array}{c}\text { Total } \\
\text { Patents }\end{array}$ & Inventor & Company & Patents & $\begin{array}{c}\text { Total } \\
\text { Patents }\end{array}$ \\
\hline \multirow{4}{*}{$\begin{array}{l}\text { Tongtong } \\
\text { Wang }\end{array}$} & $\begin{array}{l}\text { CORIXA, } \\
\text { Corporation }\end{array}$ & 14 & \multirow{4}{*}{17} & $\begin{array}{c}\text { Anant } \\
\text { Madabhushi }\end{array}$ & \multirow{4}{*}{ CWRU } & \multirow{4}{*}{8} & \multirow{4}{*}{8} \\
\hline & $\begin{array}{l}\text { Robert A. } \\
\text { Henderson }\end{array}$ & 1 & & & & & \\
\hline & $\begin{array}{c}\text { Teresa M. } \\
\text { Foy }\end{array}$ & 1 & & & & & \\
\hline & $\begin{array}{l}\text { Tongtong } \\
\text { Wang }\end{array}$ & 1 & & & & & \\
\hline \multirow{4}{*}{$\begin{array}{l}\text { Robert A. } \\
\text { Henderson }\end{array}$} & $\begin{array}{l}\text { CORIXA, } \\
\text { Corporation }\end{array}$ & 12 & \multirow{4}{*}{15} & $\begin{array}{l}\text { Vamsidhar } \\
\text { Velcheti }\end{array}$ & \multirow{4}{*}{ CWRU } & \multirow{4}{*}{8} & \multirow{4}{*}{8} \\
\hline & $\begin{array}{l}\text { Robert A. } \\
\text { Henderson }\end{array}$ & 1 & & & & & \\
\hline & $\begin{array}{l}\text { Teresa M. } \\
\text { Foy }\end{array}$ & 1 & & & & & \\
\hline & $\begin{array}{c}\text { Tongtong } \\
\text { Wang }\end{array}$ & 1 & & & & & \\
\hline $\begin{array}{l}\text { Yoshihiro } \\
\text { Watanade }\end{array}$ & $\begin{array}{l}\text { CORIXA, } \\
\text { Corporation }\end{array}$ & 10 & 10 & Brian Gold & $\begin{array}{c}\text { PURE } \\
\text { Storage, } \\
\text { Inc. }\end{array}$ & 6 & 6 \\
\hline $\begin{array}{l}\text { Chaitanya } \\
\text { S. Bangur }\end{array}$ & $\begin{array}{l}\text { CORIXA, } \\
\text { Corporation }\end{array}$ & 7 & 7 & $\begin{array}{c}\text { Emily } \\
\text { Watking }\end{array}$ & $\begin{array}{c}\text { PURE } \\
\text { Storage, } \\
\text { Inc. }\end{array}$ & 6 & 6 \\
\hline $\begin{array}{l}\text { Gary R. } \\
\text { Fanger }\end{array}$ & $\begin{array}{l}\text { CORIXA, } \\
\text { Corporation }\end{array}$ & 7 & 7 & $\begin{array}{c}\text { Igor } \\
\text { Ostrovsky }\end{array}$ & $\begin{array}{c}\text { PURE } \\
\text { Storage, } \\
\text { Inc. }\end{array}$ & 6 & 6 \\
\hline Total & - & 56 & 56 & Total & - & 34 & 34 \\
\hline
\end{tabular}

From Table 5, we observe that, unlike previous decade, innovators work for different organizations, and in the second following ten years, innovators usually only work for one particular company. The top two inventors, Anant Madabhushi and Vansidhar Velcheti, put a lot effort for CWRU to cooperatively create 8 patents. The result indicates that both of the two inventors take the mutual research advantages with CWRU. Schmid and Fajebe (2019) specify that university patents have a particularly deep and wide impact on subsequent technological change. Schmid and Fajebe (2019) attempt to examine the influential impact of university's 
policy upon the technological innovation, and therefore propose that universities' commitment is the powerful engine for advancing technological innovation of corporations. It seems particular true from the evidence of CWRU patents outcome. The rest top three innovators effort for the 6 patents of Pure Storage Inc. Their research performances are also incredibly impressive. Surprisingly, IBM innovators haven't ranked as the top five, even though 19 innovators of IBM have relatively preceding research aggressively. Within the recent three years, IBM has published 7 patents related with AI technology of NSCLC medication treatment. IBM's R\&D power is very promising future to hold the public attention. As noticed, IBM puts its effort to bring Watson into the health care industry in 2011. Since then, Watson has made nearly 50 announcements about partnerships which intend to develop new AI-enabled tools for medicine.

To sum up, the company's R\&D capability is relatively important to get the innovators' support. As CORIXIA Corporation is merged by GSK, top researchers like Tongtong Wang and Robert A. Henderson are not productive comparing with the previous decade. This is obviously considered as a lost for NSCLC patients, because innovators have no longer supported CORIXIA Corporation. Consequently, they lost their productivity of relative innovation while they don't have published any AI patent after 2010. Although there are few outstanding researchers like Anant Madabhushi and Vamsidhar Velcheti, the prosperous patent publishing in the related field somehow has gone with the CORIXIA Corporation.

\section{Conclusions}

This study applies keywords searching technique by the use of the patent search software INNOVUE. Based on previous research, we identify 10 related keywords and 10 related IPC code to crossly search patent data from 1986 to 2021, which have shown in the patents as to the title, abstract, content and related technical fields. Comparing 2001-2010 years with 2011-2020 years, we identify the patent trend changes in the two decades. Further, we analyze the growing trend and forecast the future progress of AI application in medical development. This study also provides suggestions for governments regarding the policy and assistance being helpful for AI healthcare expansion, as well as being encouraging investors who intend to have insight for future related research of AI technology applied in NSCLC treatment. From numerous anticipations, we expect that AI technology could assist current medication care system and upgrade better survival rate of NSCLC patients. This study presents insights on the phenomenon of international patent development in AI technology application of NSCLC medication treatment. Comparing two decades of patent development, this study calls on policy makers to design appropriate policies at national level. The analyses of IPC code and company R\&D capabilities allow for effective optimum resource allocation and talent distribution. This study concludes:

(1) First of all trend development, the number of $\mathrm{Al}$ technology-related patents implied in NSCLC medical treatment is increasing from 2001 to 2020. 
(2) Most of AI technology-related patents applied in NSCLC medical treatment have published in the US, nevertheless, East Asia countries become the second big source of related patent publication. Additionally, we find that diagnosis and testing are still considered as the priority of the NSCLC treatment at early-stage. However, recently the image analysis becomes more and more important in current medication stage.

(3) In the near future, the researchers can pay more attention to CWRU, IBM and Pure Storage. Their development in the related research could be very promising. Owing to their patent published number increasing, inventors are convinced that those companies are productive investment objects. Top innovators are no longer making research for many companies individually and they work together for getting better quality of patent published.

This research findings highlight concerted efforts in pushing AI technology to clinical usage and impact in future direction of NSCLC care. For patients benefit concern, we do not hope the patent development would be hindered by rare source. Instead, countries, companies and innovators can corporate with each other to fight with patients and create better chance for potential patients. Although the idea seems controvert with the patent innovation, however, the medication relative research should put patients' benefit in the first place. This study strongly advocates that high-speed technology development may break the boundary of AI handicap in the near future.

\section{Reference}

[1] Abadi, H.H.N. and Pecht, M. (2020). Artificial intelligence trends based on the patents granted by the United States patent and trademark office. IEEE Access, 8: 81633-8164

[2] Bi, W.L., Hosny, A., Schabath, M.B., Giger, M.L., Birkbak, N.J., Mehrtash, A. and Aerts, H.J. (2019). Artificial intelligence in cancer imaging: Clinical challenges and applications. A Cancer Journal for Clinicians, 69(2), 127-157.

[3] Chen, Y.S. and Chang, K.C. (2010). The relationship between a firm's patent quality and its market value: The case of US pharmaceutical industry. Technological Forecasting and Social Change, 77(1), 20-33.

[4] Jiang, F., Jiang, Y., Zhi, H., Dong, Y., Li, H. and Ma, S. (2017). Artificial intelligence in healthcare: Past, present and future. Stroke and Vascular Neurology, 2(4), 0:e000101.

[5] Kashf, D.W.A., Okasha, A.N., Sahyoun, N.A., El-Rabi, R.E. and Abu-Naser, S.S. (2018). Predicting DNA Lung Cancer Using Artificial Neural Network.

[6] Rabbani, M., Kanevsky, J., Kafi, K., Chandelier, F. and Giles, F.J. (2018). Role of artificial intelligence in the care of patients with non-small cell lung cancer. European Journal of Clinical Investigation, 48(4), e12901.

[7] Raghupathi, V. and Raghupathi, W. (2019).

Exploring science-and-technology-led innovation: A cross-country study. Journal of Innovation and Entrepreneurship, 8(1), 1-45. 
[8] Schmid, J. and Fajebe, A. (2019). Variation in patent impact by organization type: An investigation of government, university, and corporate patents. Science and Public Policy, 46(4), 589-598.

[9] Liu, Y. (2020). Application of artificial intelligence in clinical non-small cell lung cancer. Artificial Intelligence in Cancer, 1, 19-30.

[10] Wang, S., Yang, D.M., Rong, R., Zhan, X., Fujimoto, J., Liu, H. and Xiao, G. (2019). Artificial intelligence in lung cancer pathology image analysis. Cancers, 11(11), 1673.

[11] Zappa, C. and Mousa, S.A. (2016). Non-small cell lung cancer: current treatment and future advances. Translational Lung Cancer Research, 5(3), 288. 